\title{
Blood purification in intensive care patients with multiple organ dysfunction syndrome and sepsis after cardiac surgery
}

\author{
Michael Yaroustovsky, Marina Abramyan, Ekaterina Komardina, Helen Nazarova \\ Federal State Budget Institution (Bakulev National Scientific and Practical Centre for Cardiovascular Surgery, Bakulev NSPCCS), the Ministry of \\ Healthcare of the Russian Federation, 121552 Moscow, Russia.
}

Correspondence to: Prof. Michael Yaroustovsky, Federal State Budget Institution (Bakulev National Scientific and Practical Centre for Cardiovascular Surgery, Bakulev NSPCCS), the Ministry of Healthcare of the Russian Federation, Rublevskoe highway, 135, 121552 Moscow, Russia.

E-mail: mbyar@yandex.ru

How to cite this article: Yaroustovsky M, Abramyan M, Komardina E, Nazarova H. Blood purification in intensive care patients with multiple organ dysfunction syndrome and sepsis after cardiac surgery. Vessel Plus 2017;1:49-60.

Prof. Michael Yaroustovsky, the Chief of the Department of Detoxication and Endoscopy at Bakoulev Scientific
Center for Cardiovascular Surgery, Corresponding Member of RAS, is a well-known Russian scientist who has
made significant contributions to the development of modern technologies of extracorporeal blood purification
in the treatment of critical states. He owns the absolute priority in the development and the introduction into
the clinical practice of Russian clinics of modern methods of correction and maintaining homeostasis, including
albumin dialysis, combined plasma filtration and adsorption, selective hemoperfusion, etc. at extremely severe
contingent of patients of different age groups having multiple organ failure and septic complications after
cardiac surgery. He is the author of more than 270 scientific articles, including 7 monographs and the first
Russian manual on Blood purification in Intensive Care.

Article history:

Received: 11-04-2017

Accepted: 08-06-2017

Published: 27-06-2017

Key words:

Extracorporeal blood purification, acute kidney injury,

acute liver failure,

extracorporeal membrane

oxygenation,

sepsis,

selective lipopolysaccharide-

adsorption,

critical condition,

cardiovascular surgery

\section{ABSTRACT}

\begin{abstract}
Extracorporeal blood purification is becoming increasingly important in intensive therapy for multiple organ dysfunction syndrome (MODS) and sepsis, considering all of their pathophysiological aspects. The results of treatment, particularly in children, considering their anatomical and physiological features, are related to the severity and progression of organ failure, the indications that are found, the choice of method, and the timely initiation of blood purification. Multiple organ support therapy is the aim of introducing and applying blood purification today. Various extracorporeal blood purification techniques directly affect the molecular and electrolyte composition of blood and influence all structures of the human body, which can allow us to correct, recover, replace and maintain homeostasis in MODS. The potential of new extracorporeal molecular technologies allows their successful use in severe cardiac and respiratory failure, acute kidney injury and hepatic dysfunction and in complex therapy for severe infections and sepsis and extreme metabolic violations. Adult and pediatric patients after cardiac surgery with cardiopulmonary bypass form a special cohort that often requires the application of various intra- and extracorporeal techniques due to the development of MODS, infections and sepsis in the postoperative period.
\end{abstract}




\section{INTRODUCTION}

Extracorporeal blood purification is a modern medical direction based on the modification of blood components outside the patient's body aiming to change their properties or remove pathological substances that cause or support the disease. The use of these methods concerning the pathophysiological process allows us to achieve therapeutic effects, even when traditional methods are ineffective.

\section{BLOOD PURIFICATION FOR ACUTE KIDNEY INJURYIN PATIENTS WITH MULTIPLE ORGAN DYSFUNCTION SYNDROME}

Renal replacement therapy (RRT) is a routine method for intensive care patients with acute kidney injury (AKI). However, the incidence of isolated AKI in adult intensive care unit (ICU) patients does not exceed $5.7 \%{ }^{\left[{ }^{[1]}\right.}$ up to $90 \%$ of the $\mathrm{AKI}$ in this group are part of a multiple organ dysfunction syndrome (MODS), indicating the severity of the patients' condition. ${ }^{[2,3]}$ Similarly, AKI remains one of the serious complications after open heart surgery in children. The reported incidence of AKI after cardiopulmonary bypass (CPB) ranges from $23-52 \%$ with up to $17 \%$ of these patients require RRT. ${ }^{[4]}$ It prolongs the duration of ICU stays up to $3-4$ weeks and increases mortality up to $40-90 \% .{ }^{[5]}$ Isolated pediatric AKI corresponds to only $15 \%$, and it is more common in MODS. ${ }^{[6]}$

The goal of extracorporeal blood purification in the ICU today should be the treatment of MODS considering the pathophysiological aspects of it rather than the classical RRT in AKI. ${ }^{[7,8]}$ The choice of the optimal blood purification modality is based on the ability to correct water-electrolyte and metabolic imbalances and to decrease the manifestations of endo- and exotoxicosis, and other homeostatic disorders, thereby improving survival of critically ill patients. Multiple organ support therapy is an effective clinical approach. Various systems and procedures for extracorporeal blood purification including diffusion, convection, filtration, adsorption, and apheresis directly affect the molecular and electrolyte composition of the blood, allowing one to correct, recover and maintain homeostasis.

Dialysis, convection and filtration can be used today not only for RRT. Hemodialysis (HD), hemofiltration (HF) and hemodiafiltration (HDF) are pathogenically valid and effective methods in MODS. Pediatric AKI, especially in underweight children, usually requires the contemporary use of peritoneal dialysis (PD) and extracorporeal methods. Each technique has its advantages and limitations, which form an algorithm of therapeutic protocol choice. ${ }^{[9,10]}$

Cardiosurgery patients with MODS form an extremely serious group. First, one should pay attention to the left and right ventricle efficiency, level of preload, volume overload of pulmonary circulation and oxygenation index $\left(\mathrm{PO}_{2} / \mathrm{FiO}_{2}\right)$. At the time of initiating extracorporeal therapy, such patients usually have severe gas exchange and hemodynamic disturbances, which require a multicomponent inotropic (epinephrine $>0.2 \mu \mathrm{g} / \mathrm{kg} / \mathrm{min}$, dobutamine $>5 \mu \mathrm{g} / \mathrm{kg} / \mathrm{min}$, dopamine $>7 \mu \mathrm{g} / \mathrm{kg} / \mathrm{min}$ ) and mechanical circulatory support [intra-aortic balloon counterpulsation and extracorporeal membrane oxygenation (ECMO)]. Patients with MODS have an increased preload [central venous pressure (CVP) $>18 \mathrm{mmHg}$, left atrial pressure (Pla) $>20 \mathrm{mmHg}$, low oxygenation index $\left(\mathrm{PO}_{2} / \mathrm{FiO}_{2}<150\right)$, edematous syndrome, azotemia (creatinine > $350 \mu \mathrm{mol} / \mathrm{L}$, urea $>25 \mathrm{mmol} / \mathrm{L}$ ), and electrolyte (hyperkalemia) and metabolic (lactic acidosis) disorders. After the first several hours of dialysis, hemofiltration, hemodiafiltration (HD, HF, HDF), we observed preload reduction (CVP and Pla decreased $>10 \%$ ) and hemodynamic stabilization [cardiac index, left ventricular ejection fraction (LVEF) and arterial pressure] against a background of inotropic support decline, up to $25 \%$ of the prescribed dose.

In the pediatric ICU, the use of acute PD is justified as the RRT method. PD does not adversely affect hemodynamics; it requires no systemic anticoagulation or vascular access, and it excludes the emergence of disequilibrium syndrome. Moreover, this method is simple, efficient and safe, and it does not require complex expensive equipment. The indications for PD in children after cardiac surgery are oligo/anuria, hypervolemia, edematous syndrome with cardiac and respiratory insufficiency progression, azotemia and hyperkalemia. ${ }^{[5,11]} \mathrm{PD}$ allows one to decrease circulatory insufficiency, in particular, to raise mean arterial pressure (MAP) and LVEF with inotropic support decline, to normalize ventricular filling pressure and preload and postload (CVP and Pla), to optimize the circulating blood volume and correct edema syndrome [Figure 1]. The favorable effect of slow and constant filtration in PD helps reduce tissue hyperhydration, improve pulmonary gas exchange and increase the oxygenation index. Individualized programs and dosages of PD and appropriate parenteral nutrition make it possible to predict the course of AKI, along with the stabilization and further decrease of azotemia. ${ }^{[12]}$

More "aggressive" blood purification in infants is 
dictated by an inadequate PD dosing in metabolic and water-electrolyte disorders with severe edema syndrome, tissue hyperhydration and the preservation of azotemia. Carrying out constant HF/HD in infants makes it possible to achieve the necessary fluid balance, and decreases in CVP and Pla are accompanied by MAP and LVEF increases, which allow inotropic support reduction in some cases. ${ }^{[13]}$

We are in strong agreement with researchers who believe that hemodynamic and gas exchange improvements are associated with the optimization of circulating blood volume and plasma colloid osmotic pressure. ${ }^{[5]}$ We also think that blood purification's positive effects are implemented by filtration of interstitial fluid excess and reduction of myocardial and pulmonary edema. ${ }^{[8]}$

The effectiveness of any blood purification method in cardiosurgery patients depends on the adequate correction of electrolyte (hyperkalemia, hyper- and/or hyponatremia) and metabolic (lactatemia, acidosis, alkalosis) disorders and azotemia. Hyperkalemia is caused by acute kidney injury, catabolism, rhabdomyolysis and reperfusion after crash syndrome, hemolysis and disseminated intravascular coagulation. It is often aggravated by concomitant metabolic acidosis and is an additional cardiotoxic factor.

The diffusion and filtration rates during continuous veno-venous hemofiltration (CVVHF) or CVVHF dialysis permit one to correct azotemia, hyperkalemia and metabolic parameters and control them later. ${ }^{[14]}$ In contrast to PD, constant or intermittent extracorporeal therapy stabilizes and significantly reduces the azotemia level earlier, quickly corrects hyperkalemia and metabolic disorders, and provides clearance of exo- and endotoxins.

Extracorporeal blood purification in adult and pediatric MODS patients is used for both renal and extrarenal

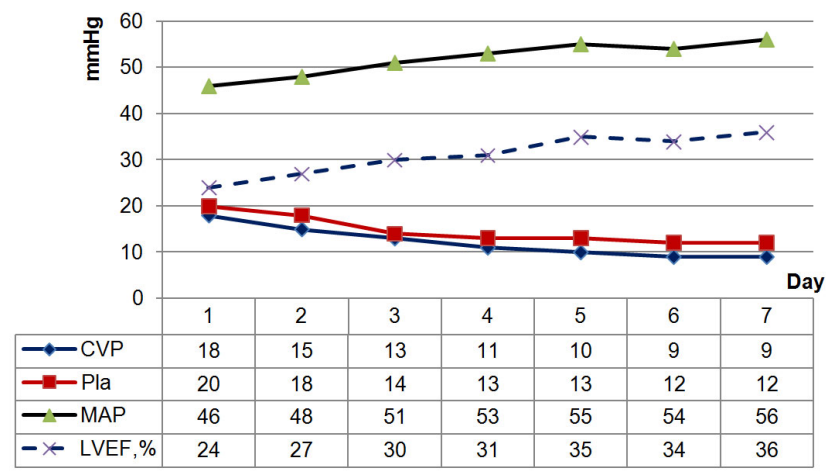

Figure 1: Hemodynamics parameters during peritoneal dialysis. CVP: central venous pressure; Pla: left atrial pressure; MAP: mean arterial pressure; LVEF: left ventricle ejection fraction indications. Its elimination of medium-molecular depressive factors, which are elevated in MODS and sepsis, ${ }^{[2,8]}$ and correction of hyperkalemia and azotemia prevent the development of immune paralysis and uremic polyserositis. During extracorporeal procedures, it is possible to normalize body temperature and temperature balance as a whole.

The ability to perform the necessary volume of infusion-transfusion therapy in anuria and tissue hyperhydration without the risk of hypervolemia is very important.

Because of the high risk of both hypo- and hypercoagulation in cardiosurgery patients, choosing the anticoagulation mode carefully is also very important.

\section{CVVHF IN CONJUNCTION WITH ECMO IN CHILDREN WITH CRITICAL HEART FAILURE AND ACUTE KIDNEY INJURY AFTER CARDIAC SURGERY}

Due to the significant expansion of cardiac surgery worldwide, the number of ECMO patients in the near postoperative period has increased significantly. Severe cardiac and/or respiratory failure is accompanied by cardiogenic shock and hypoxia with MODS and AKI development. These patients have hypervolemia and electrolyte disorders (hyperkalemia, hypocalcemia, hypo- or hypernatremia, tissue hyperhydration), which can increase azotemia and metabolic disorders. Thus, continuous hemofiltration in conjunction with ECMO is a justified method of correcting the entire complex of homeostatic disorders. ${ }^{[15]}$

Many medical centers offer continuous RRT as the most manageable and effective method. ${ }^{[16]}$ We chose CVVHF, which influences various aspects of the pathogenesis of MODS, inhibits its development and progression, and helps eliminate the medium molecular weight substances, thereby contributing to a decrease in inflammatory cascade activity. ${ }^{[17]}$ In addition, the use of high volumes of replacement liquids (more than $30-35 \mathrm{~mL} / \mathrm{kg} / \mathrm{h}$ ) can be of great importance for enhancing lymphatic transport between the intercellular space, tissues and blood and for reducing the activity of the inflammatory cascade.

The results of the treatment and its cost allow the conclusion that CVVHF connected to an ECMO circuit (single circuit) is relatively simple and has advantages for intensive care patients. ${ }^{[18,19]}$ 
We have shown the successful use of CVVHF in conjunction with ECMO in children (more than 80 patients) who have undergone correction of complex congenital heart defects. ${ }^{[2]}$ This combination of different techniques in a single extracorporeal circuit allows the correction of water and electrolyte disturbances, metabolic disorders and azotemia from the first day of treatment. Moreover, the prescribed ultrafiltration volume is calculated and programmed according to the level of volemia in each specific case. The determining factors are as follows: CVP and Pla, pulmonary artery pressure, ventricular enddiastolic volumes, the volume of necessary infusion and transfusion therapy and nutritional support. Only one day after connecting CVVHF to an ECMO circuit, we observed a significant $(P<0.05)$ decrease in CVP and Pla to 15 (14-17) and 16.5 (14-18.75) $\mathrm{mmHg}$, respectively. When CVP reached $8-12 \mathrm{mmHg}$ and Pla 10-14 mmHg, the RRT mode was switched to isovolemic ultrafiltration [Figure 2].

Since a significant amount of liquid is exchanged daily during CVVHF in conjunction with ECMO, the use of automated volumetric control devices (infusomats) is a prerequisite to avoid possible errors and maintain clear liquid balance. It should be noted that passive (non-automated) ultrafiltration in CVVHF is always associated with an inaccurate calculation of the liquid balance and is dangerous, particularly in children weighing up to $10 \mathrm{~kg} \cdot{ }^{[20]}$

According to the proposed scheme (CVVHF + ECMO in single circuit), a substitute is administered in one of the patient's central veins ( $v$. femoralis, v. subclavia or $v$. jugularis) by means of infusomat. The type of replacement solution is determined directly in each case, depending on the level of potassium and other blood electrolytes. As a substitute, we used crystalloid solutions of Duosol (BBRAUN, Germany) with bicarbonate buffer and variable potassium content ( 2 or $4 \mathrm{mmol} / \mathrm{L}$ ). The hemofiltration "dose" is set at a

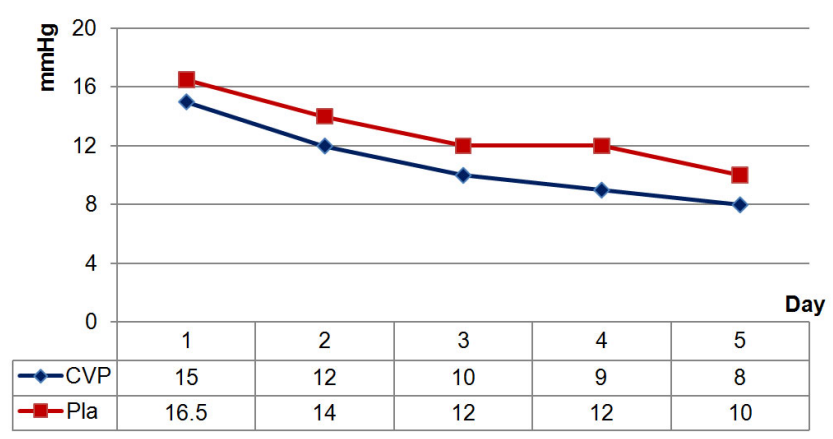

Figure 2: Dynamics of CVP and Pla during CVVHF in conjunction with ECMO. CVP: central venous pressure; Pla: left atrial pressure; CVVHF: continuous veno-venous hemofiltration; ECMO: extracorporeal membrane oxygenation rate of $20-40 \mathrm{~mL} / \mathrm{kg} / \mathrm{h}$ to ensure the required quality of the procedure. Anticoagulation was carried out for the combined ECMO and HF single circuit with the use of unfractionated heparin; the activated clotting time was maintained within 180-200 s.

The circuit lifetime should not exceed $48 \mathrm{~h}$. Since the aim of the CVVHF connection was to perform RRT, its duration was determined by the dynamics of the renal dysfunction and the clinical state of the child.

The use of methods of extracorporeal blood purification should be considered a "bridge" to the recovery of kidney function. Given the obvious need to control the electrolyte, acid-base and water balance in patients with AKI, the use of CVVHF may be considered a method of supporting kidney function that is similar to breathing assistance by mechanical ventilation or cardiac and respiratory support by ECMO. ${ }^{[19,21]}$ The primary goal of RRT is to prevent undesirable additional effects by reducing uremic intoxication and maintaining the "internal environment" as close to the physiological state as possible, without adversely affecting the functions of the patient's vital organs and system. ${ }^{[20]}$

\section{EXTRACORPOREAL BLOOD PURIFICATION IN INTENSIVE CARE PATIENTS WITH ACUTE LIVER FAILURE}

Acute liver failure (ALF) is a rare but severe and life-threatening condition in patients after cardiac surgery. In most cases, ALF develops in the setting of MODS. The frequency of MODS in patients after cardiac surgery with CPB is relatively low, but the occurrence of liver dysfunction increases mortality to almost absolute values. ${ }^{[22-24]}$ Despite the progress of conservative treatment for ALF and the development of new therapeutic recommendations, blood purification continues to play an important role in this case. Extracorporeal methods have the ability to eliminate both hydrophobic albumin-bound and water-soluble substances, thereby limiting the extent of hepatocyte damage and providing time for the organ's recovery or performing liver transplantation for the patient. ${ }^{[25,26]}$ Extracorporeal therapy also helps achieve one of the most important goals in this case -- increasing the albumin binding capacity by eliminating albumin-bound toxic substances.

Currently, there are two groups of extracorporeal methods to support liver functions: the systems containing cells (human or animal hepatocytes), and techniques without biological substrates. 
Extracorporeal methods based on patient's blood perfusion through exogenous hepatocytes were not widely used due to their high complexity and cost, the insufficient cell mass for liver regeneration $(\geq 400 \mathrm{~g}$ would be needed) as well as low biocompatibility and infection risk.

Modern extracorporeal blood purification methods without using biological components comprise high-volume plasma exchange, albumin dialysis [Molecular Adsorbent Recirculating System (MARS ${ }^{\circledR}$ )], single-pass albumin dialysis (SPAD) and methods that combine plasma separation and adsorption [Fractionated Plasma Separation and Adsorption (FPSA) Prometheus $\left.\left.{ }^{\circledR}\right)\right]$.

In acute liver failure, plasma exchange provides a reduction in bilirubinemia, but this is achieved only at high exchange volumes (up to $10 \mathrm{~L}$ ), and the lack of specificity and high risk of allergic and infectious complications reduce the benefits and limit the use of this method. ${ }^{[27,28]}$ SPAD therapy uses standard equipment for kidney replacement therapy with a highly porous membrane dialyzers and albumin containing dialysis solutions to remove hydrophobic substances.

The emergence of new hi-tech techniques, such as albumin dialysis (MARS-therapy) and fractionated plasma separation and adsorption (Prometheustherapy), allow optimistic results to be obtained with complex intensive therapy for this severe category of patients. ${ }^{[29]}$

The beneficial effect of these procedures on clinical and laboratory parameters is explained by the removal of vasoactive substances and toxins, leading to improvements in organ and tissue perfusion, hemodynamic parameters and kidney function and reducing portal hypertension, intracranial pressure and hepatic encephalopathy. ${ }^{[30,31]}$ The experience from implementing this therapy in adults allows the use of extracorporeal liver support to be recommended in pediatric practice. ${ }^{[32-34]}$

MARS-therapy is a method of albumin dialysis that uses a filter permeable to substances with a molecular weight of up to $50 \mathrm{kDa}$. The toxins accumulated on the filter membrane are subsequently bound to the donor albumin used as a dialysate. Simultaneously, the albumin dialysate is purified by passing through activated carbon, anion exchange resin and a lowpermeability dialyzer, which provides a link between the albumin circuit and the traditional bicarbonatebased dialysis solution. Thus, the simultaneous selective removal of albumin-bound and water-soluble substances has become possible. ${ }^{[35,36]}$

The principle of Prometheus-therapy is based on plasma separation on the AlbuFlow filter, the membrane of which is permeable to molecules of up to $250 \mathrm{kD}$, including albumin, clotting factors and fibrinogen. Separated plasma regenerates when it successively passes through absorbers with ion exchange and neutral resin. Removal of low molecular weight water soluble compounds is provided by the performance of HF or HD. This technique is the most effective for eliminating albumin-bound toxins such as unconjugated bilirubin and bile acids. ${ }^{[37,38]}$

In assessing the safety and efficacy of MARS and Prometheus therapies in adult patients with ALF after cardiac surgery, we analyzed the dynamics of hydrophobic and hydrophilic toxic substance concentrations as well as the severity of hepatocyte cytolysis and the impairment of liver synthetic function. A key aspect in the evaluation of MARS and Prometheus liver support system safety in patients after cardiac surgery was the absence of a negative influence on hemodynamics and lung oxygenation function. In evaluating the safety of these systems, monitoring the dynamics of serum albumin is recommended, which is important in the setting of initial dysproteinemia in ALF and the use of high permeability hemo- or plasma filters. According to several authors, the serum albumin concentration during MARS-therapy remains unchanged because the diameter of the filter pores ( $50 \mathrm{kDa}$ ) does not exceed the size of the albumin molecule (65 kDa). ${ }^{[26,38]}$ However, the albumin loss during Prometheus-therapy can reach $3 \mathrm{~g} / \mathrm{L}(P=0.055) .{ }^{[31,39]}$ We observed no significant negative dynamics of serum albumin [oscillations: 32 (30-35) and 30 (2635) $\mathrm{g} / \mathrm{L}, P=0.052$, before and after MARS-therapy; $33(31-34)$ and $31(28-36) \mathrm{g} / \mathrm{L}, P=0.051$, before and after Prometheus-therapy], which is probably due to the adequate routine correction of hypoproteinemia in patients with ALF. ${ }^{[39]}$ Likewise, despite published data on the loss of coagulation factors during Prometheus-therapy, ${ }^{[40]}$ we did not observe clinically significant hemorrhagic complications.

The use of both liver support systems in cardio surgical patients provided a significant reduction in the total bilirubin concentration, and Prometheustherapy allowed the clearance of unconjugated bilirubin. During MARS-therapy, the initial level of total bilirubin was $230(181-256) \mu \mathrm{mol} / \mathrm{L}$ whereas during Prometheus-therapy, it was 333 (189-450) $\mu \mathrm{mol} / \mathrm{L}$; the concentrations of unconjugated bilirubin were 103 (72-135) and 119 (74-166) $\mu \mathrm{mol} / \mathrm{L}$, respectively. 
Extracorporeal liver support provided a statistically significant reduction in total bilirubin concentration (8.6\% for MARS-therapy $(P=0.028)$ and $33 \%$ for Prometheus $(P<0.001))$. Prometheus-therapy also provided significant clearance of unconjugated bilirubin $(29 \%, P=0.003))^{[39]}$ These results agree with data from other researchers, who reported a total bilirubin reduction of $26-59 \%$ during Prometheus and of $23 \%$ during albumin dialysis. ${ }^{[41-43]}$ Such differences in reducing the level of total bilirubin are primarily due to the technical characteristics of the membranes and the different rates of perfusion and albumin dialysate/ plasma.

During our study, we noted positive dynamics of the serum aminotransferase levels, which reflect hepatocyte cytolysis. This trend indirectly indicated a decrease in the degree of liver parenchyma lesion. The decrease of ASAT and ALAT was $15.5 \%$ ( $P$ $=1.0)$ and $43 \%(P=0.31)$ during MARS-therapy, respectively, and $8 \%(P=0.79)$ and $26 \%(P=0.0005)$ during Prometheus-therapy, respectively. According to foreign colleagues, Prometheus-therapy decreases serum aminotransferase to $40-55 \%$ in patients with predominantly toxic ALF. ${ }^{[44]}$

In our study, serum cholinesterase was the marker of normalization of liver synthetic function. Its growing concentration in the setting of extracorporeal liver support suggests a positive effect of the treatment. This conclusion is also confirmed by the observed growth of the initially low level of antithrombin III in patients enrolled in the study [MARS-therapy: $31 \%$ (30-33\%), Prometheus-therapy: 51\% (33-62\%)]. Since most of the patients were receiving RRT at the time of enrollment, the baseline levels of azotemia and ammonia were low. However, in spite of the performed blood purification procedures, there were significant positive changes of urea and creatinine levels, which indicates that the efficiency of MARS and Prometheus methods in eliminating water-soluble substances was sufficiently high to allow their use in AKI and ALF in the setting of MODS. ${ }^{[39,44]}$

According to many authors, the impact of extracorporeal blood purification methods on survival rate in ALF was statistically insignificant. However, the results of multi-center prospective randomized studies for this issue were ambiguous.

In the HELIOS study including 145 patients with acute-on-chronic liver dysfunction receiving 8-10 Prometheus procedures, the increase in total survival rate was statistically insignificant. However, the subgroup of patients with the most severe condition, i.e. with hepatorenal syndrome type I and MELD score above 30 , a statistically significant increase in survival rate was found. ${ }^{[45]}$ Taking such results into account, we recommend to perform a differentiated evaluation of extracorporeal therapy effectiveness, including its effect on survival rate in specific patient subgroups.

At the A.N. Bakulev NSPCCS, the MARS-therapy method was successfully applied for the first time in children with MODS after the radical correction of congenital heart disease. Patients with MODS developed severe hepatic failure along with heart (EF $<40 \%$, required inotropic support), respiratory and renal failure. We observed the failure of conservative therapy for hepatic insufficiency, progressive increases in bilirubin (up to $500 \mu \mathrm{mol} / \mathrm{L}$ ) and cytolytic syndrome with an increase of ASAT and ALAT enzymes (more than $200 \mathrm{U} / \mathrm{L})$. During MARS-therapy, positive dynamics were more evident in children than in adults. The reduction of jaundice was noted at the end of the procedure (duration: 16-18 h), which indicates the effective elimination of bilirubin and bile acids. This fact can be explained by the ratio of the child's body surface area to the sorption capacity of the columns with activated carbon and ion-exchange resin. For example, the total bilirubin decrease in a child weighing less than $6 \mathrm{~kg}$ (age: 4 months) at the end was approximately $75 \%$ and stayed constant over $12 \mathrm{~h}$. The unconjugated bilirubin decrease in this patient amounted to $80 \%$ of the initial value, continued $12 \mathrm{~h}$ later and reached almost $90 \%$. Conjugated bilirubin decreased less significantly: by $70 \%$ directly at the end of the procedure and by $55 \%$ in $12 \mathrm{~h}$ [Figure 3].

As observed for other types of blood purification, the liver support system's effects on the circulatory and respiratory systems are very important for using these methods in intensive therapy for children after cardiac surgery. By the end of MARS-therapy, MAP exceeded $25 \%$ of the baseline, but the need for inotropic support decreased. ${ }^{[32,33]}$

Due to the large heat loss during extracorporeal

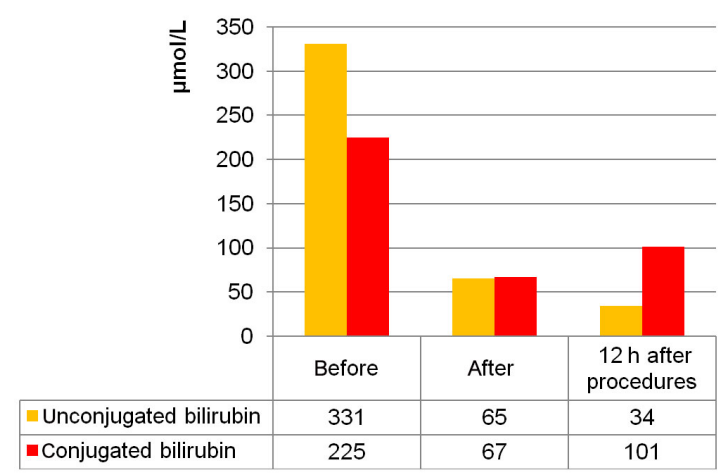

Figure 3: Dynamics of the fractions of bilirubin during molecular adsorbent recirculating system-therapy (4-month patient) 
blood purification in children, it is important to prevent hypothermia. Hypothermia can lead to cardiac output decrease by peripheral vasospasm and an increase in TPVR and post-load. To avoid heat loss during MARS-therapy in children, it is necessary to use a heat exchanger and other physical heating means and to establish a high temperature $\left(38-39^{\circ} \mathrm{C}\right)$ on the bicarbonate line. ${ }^{[44]}$

\section{EXTRACORPOREAL BLOOD PURIFICATION IN COMPLEX INTENSIVE THERAPY FOR SEPSIS IN ADULT AND PEDIATRIC PATIENTS AFTER OPEN- HEART SURGERY}

Sepsis and septic shock are among the most common causes of death in critically ill patients in the ICU. Over the last decade, clinics worldwide have noted a trend towards a decrease in the frequency of Gram-positive bacteria and an increase in the frequency of Gramnegative bacteria within microbiological studies.

A structural component of the membrane of gram-negative microorganisms is bacterial lipopolysaccharide (or endotoxin), which is the main trigger of both sepsis and a cascade of inflammatory reactions. ${ }^{[46]}$ When entering the systemic bloodstream from a focus of infection (e.g. pneumonia, mediastinitis) or natural reservoir (for example, the gastrointestinal tract, particularly after CPB), endotoxin interacts with competent cells of the immune system as a hormone and activates the synthesis of a wide range of mediators. The excess production of which determines the clinical manifestations of sepsis, such as systemic endothelial damage, decreased vascular tone, hypotension, cardiovascular hyporeactivity, fever, microcirculatory disorder, activation of hemostatic system factors, tissue hypoperfusion, hypoxia and multi-organ failure. ${ }^{[47,48]}$ The development of microcirculatory disorders and tissue hypoxia in the gastrointestinal tract creates conditions for bacterial translocation. Thus, the vicious circle initiated by lipopolysaccharide is closed. ${ }^{[49,50]}$

The pathogenic chain of septic development and progression determines a need to develop and introduce new promising technologies. ${ }^{[47,51,52]}$

Modern methods of blood purification allow etiopathogenic therapy application for sepsis: to eliminate the etiotropic agent (endotoxin) by selective lipopolysaccharide (LPS)-adsorption and to remove the effector substances of systemic inflammation, replacing the functions of the affected organs and recovering the body's homeostasis by coupled plasmofiltration and adsorption (CPFA), convection and filtration techniques using ultrahigh permeable membranes. ${ }^{[53,54]}$

Many authors have observed that LPS-adsorption with PMX cartridges leads to a significant decrease in endotoxin activity levels after two consecutive procedures. ${ }^{[5]}$ Positive dynamics of the endotoxin concentration (lowering by $38 \%$ ) in patients with abdominal sepsis and septic shock were demonstrated in the European multicenter study "EUPHAS". ${ }^{[56]}$ In the MEDIC study conducted in Europe and North America on ICU patients, selective LPS-adsorption led to a decrease in the mean endotoxin activity assay (EAA) level from 0.65 to 0.45 within $12 \mathrm{~h}$ after the procedure. According to the authors, the average reduction of the endotoxin concentration $(26.1 \%)$ measured with the EAA is equivalent to a $50-100$-fold decrease in the LPS level..[57]

In the European multicentre trial, the EUPHAS trial, 28 -day survival after DHP-PMX was $53 \%$ and $32 \%$ in the study and control groups, respectively. ${ }^{[56]}$ The assessment of retrospective data on using selective LPS adsorption in 306 patients with severe sepsis enrolled in the EUPHAS 2 trial indicated that 28day mortality was $35 \%$ and $49 \%$ in the group with abdominal surgical pathology and in the group with non-abdominal pathology, respectively. ${ }^{[58]}$ Similar results were observed in earlier published Japanese ${ }^{[59-61]}$ and European studies ${ }^{[62]}$ and in the meta-analysis data regarding immobilized Polymyxin B use efficacy during sepsis..$^{[52,63]}$

Our experience with combined application of various techniques in a single circuit (LPS-adsorption + CPFA and LPS-adsorption + HD/HDF using filters with high cut-off membranes) showed their safety and pathogenic efficiency. ${ }^{[33,54]}$ The application of convection and filtration techniques (CPFA, HDF using filters with high cut-off membranes) allows the correction of water-electrolyte and metabolic disorders and azotemia, which often accompany sepsis-associated MODS. ${ }^{[64-67]}$

LPS-adsorption using Toraymyxin-PMX-20R Polymyxin B immobilized fiber cartridges was found to be effective, simultaneously acting through sorption and apheresis on bacterial endotoxin, systemic inflammatory mediators and activated immune cells. ${ }^{[59-61,68,69]}$

CPFA performs an immunomodulatory role by acting on inflammatory mediators (interleukin- $1 \beta,-6,-8$, $-10,-18$, tumor necrosis factor- $\alpha$ and others) via various mass transfer mechanisms such as diffusion, 
convection and adsorption. The advantages of CPFA include the passage of plasma (and not blood) through the sorption column, which increases the contact time with the sorption surface and improves the efficiency of the procedure. ${ }^{[65,70]}$

HDF, which is carried out using filters with high cutoff membranes (EMiC2, Fresenius, Germany; 40 kDa cut-off), eliminates substances of low and medium molecular weight without albumin or coagulation factor loss. The permeability of these filters is similar to that of the kidney glomerular basement membrane, suggesting that the therapeutic effect of HDF is more physiological. ${ }^{[66,71-73]}$

Several studies have demonstrated the beneficial effect of selective LPS-adsorption, HD/HDF (with high cut-off membranes) and CPFA in sepsis. ${ }^{[58,64-66]}$

We proposed two new techniques of combined blood purification methods in single circuit: (1) LPS-adsorption + HDF using filters with high cutoff membranes; and (2) LPS-adsorption + CPFA. In the available literature, there was no information about a similar extracorporeal therapy protocol for sepsis in cardiac surgical patients. A study of adults enrolled in these protocols, carried out at the A.N. Bakulev NSPCCS in 2009-2016, showed the safety and efficacy of the combined therapies mentioned above. ${ }^{[53,54]}$

We observed that the combination of LPS-adsorption and HDF filters with high cut-off EMiC2 membranes led to a $34 \%$ MAP increase [from $76(65-81)$ to 90 $(85-102) \mathrm{mmHg}, P<0.001]$ with reduced vasopressor and inotropic support. The increase in MAP during LPS-adsorption with CPFA was $12 \%$ with the significant decrease in vasopressor support [the dose of noradrenaline was halved from $0.2(0.15-0.3)$ to $0.1(0.05-0.15) \mu \mathrm{g} / \mathrm{kg} / \mathrm{min}, P=0.024]$. The improved oxygenation was confirmed by an increase in the oxygenation index increase (by $36 \%$ and $28 \%$ in LPSadsorption with HDF in single circuit using EMiC2 and LPS-adsorption with CPFA in single circuit, respectively). One of the mechanisms that have a favorable effect on blood oxygenation is a decrease in the intensity of the infiltrative-inflammatory lung tissue process during blood purification.

We also evaluated the efficiency of blood purification in sepsis by monitoring the dynamics of EAA, procalcitonin level, bacteriological blood and sputum examination and the clinical state of patients during the procedures. The obtained results showed a decrease of $20 \%$ in EAA (from 0.74 to $0.59, P=0.03$ ) and of approximately $70 \%$ in procalcitonin (from
8.2 to $2.44 \mathrm{pg} / \mathrm{mL}, P=0.01$ ) in patients with sepsis after two procedures of combined LPS-adsorption and HDF with EMiC2. Similar dynamics of the infectious markers were observed when conducting LPS-adsorption with CPFA: EAA decreased by $30 \%$ (from 0.77 to $0.53, P=0.003$ ) and procalcitonin by $55 \%$ (from 6.23 to $2.83 \mathrm{pg} / \mathrm{mL}, P=0.005$ ). We also observed positive dynamics in leukocytosis and hyperthermia. Both variants of combined blood purification contributed to decreases in C-reactive protein (CRP) and pro-inflammatory cytokine levels, thus confirming the decrease in the intensity of the systemic inflammation response. ${ }^{[53,54]}$

Including combined blood purification methods into the complex therapy for sepsis allowed the results of treatment to be optimized. The 28-day survival was $65 \%$ in the LPS-adsorption + HDF with EMiC2 group and $75 \%$ in the LPS-adsorption + CPFA group.

The efficiency of the proposed concept of etiopathogenetic extracorporeal therapy for gramnegative sepsis is confirmed by the favorable results obtained in cardiac surgical patients characterized by their initially severe condition and more severe course of septic complications. The combined methods of blood purification can affect either the starting factor in the early development of sepsis by endotoxin removal or the subsequent release of inflammatory mediators after immune cell activation. These therapeutic methods also maintain vital organ function in MODS development.

Our experience from using selective LPS-adsorption in adult patients with sepsis allowed us to use this method for sepsis treatment in children. Blood purification in children with sepsis is limited to RRT technologies. ${ }^{[74]}$ The principle of selective sorption use in children is absolutely innovative. No information was found in the database of the US National Library of Medicine National Institutes of Health on the use of selective LPS-adsorption for sepsis treatment in children after cardiac surgery.

The application of the smaller volume and sorption capacity of the Polymyxin B-immobilized cartridge (Toraymyxin-PMX-0.5R) is a new and promising extracorporeal technology that aims to reduce mortality from sepsis in children. Experience in selective endotoxin sorption is available only in Japan, where a study group enrolled children with abdominal pathology. The authors identified the safety and high efficiency of using Toraymyxin-PMX-0.5R cartridges. ${ }^{[75,76]}$

Today, the A.N. Bakulev NSPCCS has gained initial 
Table 1: Changes of clinical and laboratory data before and after LPS-adsorptionin the children with sepsis

\begin{tabular}{lllc}
\hline Indices & Before & After & $\boldsymbol{P}$ \\
\hline $\mathrm{MAP}, \mathrm{mmHg}$ & $65.5(63.5-74.8)$ & $80.5(76.3-83.5)$ & $\mathbf{0 . 0 1 2}$ \\
HR, beats/min & $141(126-146)$ & $135(126-141)$ & 0.19 \\
Epinephrine, $\mu \mathrm{gg} / \mathrm{kg} / \mathrm{min}$ & $0.05(0.048-0.07)$ & $0.05(0.05-0.06)$ & 0.92 \\
Body temperature, ${ }^{\circ} \mathrm{C}$ & $37.9(36.2-38.5)$ & $36.8(36.6-37.1)$ & 0.07 \\
WBC, $10^{9} / \mathrm{L}$ & $13.3(9.2-20.1)$ & $11.5(9.4-20.4)$ & 0.65 \\
$\mathrm{PLT}, 10^{9} / \mathrm{L}$ & $164(81-257)$ & $132(67-253)$ & 0.5 \\
$\mathrm{PCT}, \mathrm{ng} / \mathrm{mL}$ & $5.11(2.48-19.48)$ & $1.24(0.76-2.14)$ & 0.11 \\
EAA & $0.75(0.68-0.97)$ & $0.6(0.33-0.8)$ & 0.013 \\
Presepsin, $\mathrm{pg} / \mathrm{mL}$ & $914(673-2,812)$ & $525(288-3,343)$ & 0.44 \\
CRP, $\mathrm{mg} / \mathrm{dL}$ & $3.41(1.37-5.95)$ & $1.5(1.04-3.67)$ & 1.0 \\
\hline
\end{tabular}

LPS: lipopolysaccharide; MAP: mean arterial pressure; HR: heart rate; WBC: white blood cell; CRP: C-reactive protein; PLT: platelet; PCT: procalcitonin; EAA: endotoxin activity assay

experience with selective LPS-adsorption for sepsis treatment in children after congenital heart disease correction with cardiopulmonary bypass. Selective endotoxin adsorption was carried out using Polymyxin B-immobilized cartridges (Toraymyxin-PMX-0.5R). Ten children aged 9-48 months and weighing $6.2-14 \mathrm{~kg}$ received this procedure. In 8 cases, the infection source was ventilator-associated pneumonia, and in 1 case, it was mediastinitis and pleural empyema, and in 1 patient infected by bacterial translocation from the gut after the ECMO procedures (duration of 5 days) and dysfunction of gut. Gram-negative etiology in all cases was confirmed by microbiological examination of blood and of bronchoalveolar lavage fluid (sputum). The decision to include selective LPS-adsorption in complex therapy was made on the basis of clinical and laboratory data by a council of physicians. This study was approved by the Local Ethics Committee of the A.N. Bakulev NSPCCS.

Children before LPS-adsorption have clinical and laboratory signs of sepsis, hyperthermia (38.7$39.5{ }^{\circ} \mathrm{C}$ ), leukocytosis/leucopenia 3.3-21 $\times 10^{9} / \mathrm{L}$, subcompensated disseminated intravascular coagulation syndrome (D-dimer 530-1,580 ng/mL), procalcitonin $6.5-130 \mathrm{ng} / \mathrm{mL}$, presepsin $415-1,300$ $\mathrm{pg} / \mathrm{mL}$, EAA $0.6-1.0$, and high levels of CRP. The cardiopulmonary component prevails in the structure of organ failure, which requires multicomponent inotropic and/or vasopressor support and mechanical ventilation with high positive end expiratory pressure. Two children required RRT, daily intermittent hemodialysis, which used polysulphone high-flux membrane filters (AVpaed, Fresenius, Germany).

The results of this pilot study showed an improvement in hemodynamic and oxygenation indices, a tendency for leukocytosis and body temperature to decrease, positive X-ray dynamics and negative microbiological examination results. After LPS-adsorption, we noted decreases in the endotoxin level, procalcitonin and CRP [Table 1]. Statistical analyses were performed with SPSS software, version 20 (SPSS, Inc., USA).
The results are expressed as the median and interquartile range. The critical level of significance was set at 0.05. Nine patients were discharged, and one patient died of cerebral edema and MODS after repeated emergency surgery due to the development of an acute fistula of the prosthetic mitral valve.

Other authors also reported that this blood purification method in children has no side effects. ${ }^{[75,76]}$ Our results suggest that selective LPS-adsorption in children from middle childhood is clinically effective and safe. Endotoxin adsorption using Polymyxin B cartridges is one of the promising methods in children.

In this article, we briefly discussed some aspects of blood purification in the ICU of a cardiac surgery hospital. Over the last several decades, there have been huge changes in extracorporeal therapy use for critically ill patients. This is due to the proven efficiency of these methods in many pathological conditions and the emergence of new promising technologies. The availability of appropriate equipment and trained medical staff limiting the wide use of extracorporeal blood purification, especially in pediatric intensive care where it seems so complicated, is a thing of the past. The only issue that preserves a degree of technical complexity is creating adequate vascular access in a child and providing the possibility of performing the fulldose extracorporeal therapy according to the protocol and the assigned clinical tasks. Of course, we await the results of new multicenter randomized trials and its application for practical goals of blood purification in specific pathological conditions and clinical situations, particularly in MODS. These results will allow the most appropriate time for the initiation of blood purification to be determined, valid indications to be developed and its efficiency to be proven (convective or diffusive, continuous or intermittent, sorption or apheresis) in critically ill patients after high-risk surgery.

\section{Authors' contributions}

Conception, design and methodology of the study, results analysing and manuscript writing: $M$. 
Yaroustovsky, M. Abramyan

Collecting samples and providing clinical data: E. Komardina, H. Nazarova

Final manuscript approval: M. Yaroustovsky, M. Abramyan, E. Komardina, H. Nazarova

\section{Financial support and sponsorship None.}

\section{Conflicts of interest}

There are no conflicts of interest.

\section{Patient consent}

All patients in this study consented to all of the approved methods of treatment before their heart operation. Extracorporeal therapy was conducted in conformity with the institutional guidelines.

\section{Ethics approval}

The related study was approved by the Local Ethics Committee of the A.N. Bakulev NSPCCS.

\section{REFERENCES}

1. Uchino S, Kellum JA, Bellomo R, Doig GS, Morimatsu H, Morgera S, Schetz M, Tan I, Bouman C, Macedo E, Gibney N, Tolwani A, Ronco C; Beginning and Ending Supportive Therapy for the Kidney (BEST Kidney) Investigators. Acute renal failure in critically ill patients: a multinational, multicenter study. JAMA 2005;294:813-8.

2. Bellomo R, Ronco C. Continuous renal replacement therapy: hemofiltration, hemodiafiltration or hemodialysis. In: Ronco C, Bellomo R, Kellum JA, editors. Critical Care Nephrology. 2nd ed. Philadelphia: Saunders Elsevier; 2009. p. 1354-8.

3. Hoste EA, Kellum JA. Incidence, classification, and outcomes of acute kidney injury. Contrib Nephrol 2007;156:32-8.

4. Blinder JJ, Goldstein SL, Lee VV, Baycroft A, Fraser CD, Nelson D, Jefferies JL. Congenital heart surgery in infants: effects of acute kidney injury on outcomes. J Thorac Cardiovasc Surg 2012;143:368-74.

5. Kaddourah A, Goldstein S. Renal replacement therapy in neonates. Clin Perinatol 2014;41:517-27.

6. Gulla KM, Sachdev A, Gupta D, Gupta N, Anand K, Pruthi PK. Continuous renal replacement therapy in children with severe sepsis and multiorgan dysfunction - a pilot study on timing of initiation. Indian J Crit Care Med 2015;19:613-7.

7. Palevsky PM. Renal replacement therapy in acute kidney injury. $A d v$ Chronic Kidney Dis 2013;20:76-84.

8. Ronco C, Ricci Z, De Backer D, Kellum JA, Taccone FS, Joannidis M, Pickkers P, Cantaluppi V, Turani F, Saudan P, Bellomo R, JoannesBoyau Olivier, Antonelli M, Payen D, Prowle JR, Vincent JL. Renal replacement therapy in acute kidney injury: controversy and consensus. Crit Care 2015;19:146.

9. Bridges BC, Askenazi DJ, Smith J, Goldstein SL. Pediatric renal replacement therapy in the intensive care unit. Blood Purif 2012;34:138-48.

10. Goldstein SL. Advances in pediatric renal replacement therapy for acute kidney injury. Semin Dial 2011;24:187-91.

11. Bojan M, Gioanni S, Vouhé PR, Journois D, Pouard P. Early initiation of peritoneal dialysis in neonates and infants with acute kidney injury following cardiac surgery is associated with a significant decrease in mortality. Kidney Int 2012;82:474-81.
12. Ponce D, Balbi AL, Amerling R. Advances in peritoneal dialysis in acute kidney injury. Blood Purif 2012;34:107-16.

13. Jander A, Tkaczyk M, Pagowska-Klimek I, Pietrzykowski W, Moll J, Krajewski W, Nowicki M. Continuous veno-venous hemodiafiltration in children after cardiac surgery. Eur $J$ Cardiothorac Surg 2007;31:1022-8.

14. Iarustovskii MB, Grigor'iants RG, Strakhov DG, Banketov IaV, Geptner RA, Abramian AV, Shipova EA. A present-day variant of intermittent replacement renal therapy in patients with multiple organ failure after cardiovascular surgery. Anesteziol Reanimatol 2002;(2):49-54. (in Russian)

15. Askenazi DJ, Selewski DT, Paden ML, Cooper DS, Bridges BC, Zappitelli M, Fleming GM. Renal replacement therapy in critically ill patients receiving extracorporeal membrane oxygenation. Clin $\mathrm{J} \mathrm{Am}$ Soc Nephrol 2012;7:1328-36.

16. Hoover NG, Heard M, Reid C, Wagoner S, Rogers K, Foland J, Paden ML, Fortenberry JD. Enhanced fluid management with continuous venovenous hemofiltration in pediatric respiratory failure patients receiving extracorporeal membrane oxygenation support. Int Care Med 2008;34:2241-7.

17. Shaheen IS, Harvey B, Watson AR, Pandya HC, Mayer A, Thomas D. Continuous venovenous hemofiltration with or without extracorporeal membrane oxygenation in children. Pediatr Crit Care Med 2007;8:362-5.

18. Chen H, Yu R, Yin N, Zhou J. Combination of extracorporeal membrane oxygenation and continuous renal replacement therapy in critically ill patients: a systematic review. Crit Care 2014;18:675.

19. Fleming GM, Askenazi DJ, Bridges BC, Cooper DS, Paden ML, Selewski DT, Zappitelli M. A multicenter international survey of renal supportive therapy during ECMO: the Kidney Intervention During Extracorporeal Membrane Oxygenation (KIDMO) group. ASAIO J 2012;58:407-14.

20. Yaroustovsky MB, Abramyan MV, Nazarova EI, Komardina EV. Continuous hemofiltration in a single circuit with extracorporeal membrane oxygenation in children with critical heart failure after cardiac surgery. Clin Experiment Surg Petrovsky J 2017;5:59-67. (in Russian)

21. Gupta P, McDonald R, Chipman CW, Stroud M, Gossett JM, Imamura M, Bhutta AT. 20-year experience of prolonged extracorporeal membrane oxygenation in critically ill children with cardiac or pulmonary failure. Ann Thorac Surg 2012;93:1584-90.

22. Daas M, Plevak DJ, Wijdicks EF, Rakela J, Wiesner RH, Piepgras DG, Dunn WF, Steers JL. Acute liver failure: results of 5 years clinical protocol. Liver Transpl Surg 1995;1:210-9.

23. Cochran JB, Losek JD. Acute liver failure in children. Pediatr Emerg Care 2007;23:129-35.

24. Lee WS, McKiernan P, Kelly DA. Etiology, outcome and prognostic indicators of childhood fulminant hepatic failure in the United Kingdom. J Pediatr Gastroenterol Nutr 2005;40:575-81.

25. Saliba F, Camus C, Durand F, Mathurin P, Letierce A, Delafosse B, Barange K, Perrigault PF, Belnard M, Ichaï P, Samuel D. Albumin dialysis with a noncell artificial liver support device in patients with acute liver failure: a randomized, controlled trial. Ann Intern Med 2013;159:522-31.

26. Stange J, Hassanein TI, Mehta R, Mitzner SR, Bartlett RH. The molecular adsorbent recycling system as a liver support system based on albumin dialysis: a summary of preclinical investigations, prospective, randomized, controlled clinical trial and clinical experience from 19 centers. Artif Organs 2002;26:103-40.

27. Larsen FS, Schmidt LE, Bernsmeier C, Rasmussen A, Isoniemi H, Patel VC, Triantafyllou E, Bernal W, Auzinger G, Shawcross D, Eefsen M, Bjerring PN, Clemmesen JO, Hockerstedt K, Frederiksen HJ, Hansen BA, Antoniades CG, Wendon J. High-volume plasma 
exchange in patients with acute liver failure: an open randomised controlled trial. J Hepatol 2016;64:69-78.

28. Davenport A. Extracorporeal support for patients with hepatic failure. Hemodial Int 2003; 7:256-63.

29. Saliba F, Samuel D. Artificial liver support: a real step forward. Minerva Med 2015;106:35-43.

30. Bañares R, Nevens F, Larsen FS, Jalan R, Albillos A, Dollinger M, Saliba F, Sauerbruch T, Klammt S, Ockenga J, Pares A, Wendon J, Brünnler T, Kramer L, Mathurin P, de la Mata M, Gasbarrini A, Müllhaupt B, Wilmer A, Laleman W, Eefsen M, Sen S, Zipprich A, Tenorio T, Pavesi M, Schmidt HH, Mitzner S, Williams R, Arroyo $\mathrm{V}$; RELIEF study group. Extracorporeal albumin dialysis with the molecular adsorbent recirculating system in acute-on-chronic liver failure: the RELIEF trial. Hepatology 2013;57:1153-62.

31. Kribben A, Gerken G, Haag S, Herget-Rosenthal S, Treichel U, Betz C, Sarrazin C, Hoste E, Van Vlierberghe H, Escorsell A, Hafer C, Schreiner O, Galle PR,Mancini E, Caraceni P, Karvellas CJ, Salmhofer H, Knotek M, Ginès P, Kozik-Jaromin J, Rifai K; HELIOS Study Group. Effects of fractionated plasma separation and adsorption on survival in patients with acute-on-chronic liver failure. Gastroenterology 2012;142:782-9.

32. Rosenthal $P$. Is the molecular adsorbent recirculating system the answer for children with acute liver failure? Liver Transpl 2015;21:277-8.

33. Schaefer B, Schmitt CP. The role of molecular adsorbent recirculating system dialysis for extracorporeal liver support in children. Pediatr Nephrol 2013;28:1763-9.

34. Yaroustovsky MB, Abramyan MV, Komardina EV. Methods of molecular transfusion in intensive care of critical states in pediatric postoperative cardiac surgery patients. Ann Russ Acad Med Sci 2016;71:341-9. (in Russian)

35. Mitzner SR, Stange J, Klammt S, Risler T, Erley CM, Bader BD, Berger ED, Lauchart W, Peszynski P, Freytag J, Hickstein H, Loock J, Löhr JM, Liebe S, Emmrich J, Korten G, Schmidt R. Improvement of hepatorenal syndrome with extracorporeal albumin dialysis MARS: results of a prospective, randomized, controlled clinical trial. Liver Transpl 2000;6:277-86.

36. Vaid A, Chweich H, Balk EM, Jaber BL. Molecular adsorbent recirculating system as artificial support therapy for liver failure: a meta-analysis. ASAIO J 2012;58:51-9.

37. Laleman W, Wilmer A, Evenepoel P, Elst IV, Zeegers M, Zaman Z, Verslype C, Fevery J, Nevens F. Effect of Prometheus liver assist system on systemic hemodynamics in patients with cirrhosis: a randomized controlled study. World J Gastroenterol 2008;14:2065-71.

38. Oppert M, Rademacher S, Petrasch K, Jörres A. Extracorporeal liver support therapy with Prometheus in patients with liver failure in the intensive care unit. Ther Apher Dial 2009;13:426-30.

39. Yaroustovsky MB, Abramian MV, Komardina EV, Rep'eva EV, Nazarova EI, Krotenko NP, Geptner RA. Extracorporeal methods of hematological correction in patients with acute liver insufficiency after cardiac surgery. Anesteziol Reanimatol 2014;59:4-10. (in Russian)

40. Meijers BKI, Verhamme P, Nevens F, Hoylaerts MF, Bammens B, Wilmer A, Arnout J, Vanrenterghem Y, Evenepoel P. Major coagulation disturbances during fractionated plasma separation and adsorption. Am J Transplant 2007; 7:2195-9.

41. Gong D, Ji D, Zhu D, Xu B, Liu Z. Efficient removal of serum bilirubin by a novel artificial liver support system using albumin convection: a pilot study. Blood Purif 2012;34:201-8.

42. Donati G, La Manna G, Cianciolo G, Grandinetti V, Carretta E, Cappuccilli M, Panicali L, Iorio M, Piscaglia F, Bolondi L, Colì L, Stefoni S. Extracorporeal detoxification for hepatic failure using molecular adsorbent recirculating system: depurative efficiency and clinical results in a long-term follow-up. Artif Organs 2014;38:125-34.
43. Tsipotis E, Shuja A, Jaber BL. Albumin dialysis for liver failure: a systematic review. Adv Chronic Kidney Dis 2015;22:382-90.

44. Yaroustovsky MB, Abramyan MV, Krotenko NP, Komardina EV. Methods of molecular transfusion in the intensive therapy of critical states. Ann RussAcad Med Sci 2016;71:281-7.

45. Rifai K, Kribben A, Gerken G, Haag S, Herget-Rosenthal S, Treichel U, Betz C, Sarrazin C, Van Vlierberghe H, Hoste E, Escorsell A, Gines P, Hafer C, Schuchmann M, Galle PR, Bernardi M, Caraceni P, Abeles D, Berr F, Knotek M, Kozik-Jaromin J. Extracorporeal liver support by fractionated plasma separation and adsorption (Prometheus) in patients with acute-on-chronic liver failure (HELIOS study): a prospective randomized controlled multicenter study. J Hepatol 2010;52:S3.

46. Marshall JC. Endotoxin in the pathogenesis of sepsis. Contrib Nephrol 2010;167:1-13.

47. Hanna W, Wong HR. Pediatric sepsis: challenges and adjunctive therapies. Crit Care Clin 2013;29:203-22.

48. Kaukonen KM, Bailey M, Suzuki S, Pilcher D, Bellomo R. Mortality related to severe sepsis and septic shock among critically ill patients in Australia and New Zealand, 2000-2012. JAMA 2014;311:1308-16.

49. Berthet J, Damien P, Hamzeh-Cognasse H, Arthaud CA, Eyraud MA, Zéni F, Pozzetto B, McNicol A, Garraud O, Cognasse F. Human platelets can discriminate between various bacterial LPS isoforms via TLR4 signaling and differential cytokine secretion. Clin Immun 2012;145:189-200.

50. Bosmann M, Ward PA. The inflammatory response in sepsis. Trends Immunol 2013;34:129-36.

51. Dellinger RP, Levy MM, Rhodes A, Annane D, Gerlach H, Opal SM, Sevransky JE, Sprung CL, Douglas IS, Jaeschke R, Osborn TM, Nunnally ME, Townsend SR, Reinhart K, Kleinpell RM, Angus DC, Deutschman CS, Machado FR, Rubenfeld GD, Webb SA, Beale RJ, Vincent JL, Moreno R; Surviving Sepsis Campaign Guidelines Committee including the Pediatric Subgroup. Surviving sepsis campaign: international guidelines for management of severe sepsis and septic shock: 2012. Crit Care Med 2013;41:580-637.

52. Zhou F, Peng Z, Murugan R, Kellum JA. Blood purification and mortality in sepsis: a meta-analysis of randomized trials. Crit Care Med 2013;41:2209-20.

53. Yaroustovsky M, Abramyan M, Krotenko N, Popov D, Plyushch M, Rogalskaya E. A pilot study of selective lipopolysaccharide adsorption and coupled plasma filtration and adsorption in adult patients with severe sepsis. Blood Purif 2015;39:210-7.

54. Yaroustovsky M, Abramyan M, Krotenko N, Popov D, Plyushch M, Rogalskaya E, Nazarova H. Combined extracorporeal therapy for severe sepsis in patients after cardiac surgery. Blood Purif 2014;37:39-46.

55. Kojika M, Sato N, Yaegashi Y, Suzuki Y, Suzuki K, Nakae H, Endo $\mathrm{S}$ : Endotoxin adsorption therapy for septic shock using polymyxin B-immobilized fibers (PMX): evaluation by high-sensitivity endotoxin assay and measurement of the cytokine production capacity. Ther Apher Dial 2006;10:12-8.

56. Cruz DN, Antonelli M, Fumagalli R, Foltran F, Brienza N, Donati A, Malcangi V, Petrini F, Volta G, Bobbio Pallavicini FM, Rottoli F, Giunta F, Ronco C. Early use of polymyxin B hemoperfusion in abdominal septic shock: the EUPHAS randomized controlled trial. JAMA 2009;301:2445-52.

57. Marshall JC, Foster D, Vincent JL, Cook DJ, Cohen J, Dellinger RP, Opal S, Abraham E, Brett SJ, Smith T, Mehta S, Derzko A, Romaschin A; MEDIC study. Diagnostic and prognostic implications of endotoxemia in critical illness: results of the MEDIC study. $J$ Infect Dis 2004;190:527-34.

58. Cruz DN. Polymyxin B hemoperfusion: matching the cure to the disease. Crit Care Med 2014;42:1309-10. 
59. Mitaka C, Tsuchida N, Kawada K, Nakajima Y, Imai T, Sasaki S. A longer duration of polymyxin B-immobilized fiber column hemoperfusion improves pulmonary oxygenation in patients with septic shock. Shock 2009;32:478-83.

60. Tanaka Y, Okano K, Tsuchiya K, Yamamoto M, Nitta K. Polymyxin $\mathrm{B}$ hemoperfusion improves hemodynamic status in patients with sepsis with both Gram-negative and non-Gram-negative bacteria. $J$ Clin Exp Nephrol 2016;1:4.

61. Takahashi M, Takeuchi H, Kawakubo H, Nakamura R, Takahashi T, Wada N, Saikawa Y, Omori T, Kitagawa Y. Effectiveness of polymyxin B-direct hemoperfusion (PMX-DHP) therapy using a polymyxin B-immobilized fiber column in patients with postesophagectomy sepsis. Esophagus 2014;11:189-96.

62. Vincent JL, Laterre PF, Cohen J, Burchardi H, Bruining H, Lerma FA, Wittebole X, De Backer D, Brett S, Marzo D, Nakamura H, John S. A pilot-controlled study of a polymyxin B-immobilized hemoperfusion cartridge in patients with severe sepsis secondary to intra-abdominal infection. Shock 2005;23:400-5.

63. Cruz DN, Perazella MA, Bellomo R, de Cal M, Polanco N, Corradi V, Lentini P, Nalesso F, Ueno T, Ranieri VM, Ronco C. Effectiveness of polymyxin B-immobilized fiber column in sepsis: a systematic review. Crit Care 2007;11:R47.

64. Berto P, Ronco C, Cruz D, Melotti RM, Antonelli M. Costeffectiveness analysis of polymyxin-B immobilized fiber column and conventional medical therapy in the management of abdominal septic shock in Italy. Blood Purif 2011;32:331-40.

65. Berlot G, Agbedjro A, Tomasini A, Bianco F, Gerini U, Viviani M, Giudici F. Effects of the volume of processed plasma on the outcome, arterial pressure and blood procalcitonin levels in patients with severe sepsis and septic shock treated with coupled plasma filtration and adsorption. Blood Purif 2014;37:146-51.

66. Haase M, Bellomo R, Baldwin I, Haase-Fielitz A, Fealy N, Davenport P, Morgera S, Goehl H, Storr M, Boyce N, Neumayer HH. Hemodialysis membrane with a high-molecular-weight cut-off and cytokine levels in sepsis complicated by acute renal failure: a phase 1 randomized trial. Am J Kidney Dis 2007;50:296-304.

67. Rimmelé Th, Kellum J. Clinical review: blood purification for sepsis. Crit Care 2011;15:205.

68. Esteban E, Ferrer R, Alsina L, Artigas A. Immunomodulation in sepsis: the role of endotoxin removal by polymyxin B-immobilized cartridge. Mediators Inflamm 2013;2013:507539.

69. Yaroustovsky M, Abramyan M, Krotenko N, Popov D, Plyushch M, Popok Z. Endotoxin adsorption using polymyxin B immobilised fibre cartridges in severe sepsis patients following cardiac surgery. Int $J$ Artif Organs 2014;37:299-307.

70. Hu D, Sun S, Zhu B, Mei Z, Wang L, Zhu S, Zhao W. Effects of coupled plasma filtration adsorption on septic patients with multiple organ dysfunction syndrome. Ren Fail 2012;34:834-9.

71. Lee D, Haase M, Haase-Fielitz A, Paizis K, Goehl H, Bellomo R. A pilot, randomized, double-blind, cross-over study of high cut-off versus high-flux dialysis membranes. Blood Purif 2009;28:365-72.

72. Morgera S, Haase M, Kuss T, Vargas-Hein O, Zuckermann-Becker H, Melzer C, Krieg H, Wegner B, Bellomo R, Neumayer HH. Pilot study of the effects of high cutoff hemofiltration on the need for norepinephrine in septic patients with acute renal failure. Crit Care Med 2006;34:2099-104.

73. Naka T, Haase M, Bellomo R. "Super high-flux" or "high cut-off" hemofiltration and hemodialysis. Contrib Nephrol 2010;166:181-9.

74. Liu JP, Wang XW, Qie LP. Disease indicators for sepsis and analysis of sepsis treatment in children using the continuous blood purification technique. Genet Mol Res 2015;4:5685-93.

75. Hirakawa E, Ibara S, Tokuhisa T, Hiwatashi S, Hayashida Y, Maede Y, Matsui T, Nakazawa Y, Inoue T, Kodaira Y. Septic neonate rescued by polymyxin B hemoperfusion. Pediatr Int 2013;55:e70-2.

76. Morishita Y, Kita Y, Ohtake K, Kusano E, Hishikawa S, Mizuta K, Kawarasaki H. Successful treatment of sepsis with polymyxin-B immobilized fiber hemoperfusion in a child after living donor liver transplantation. Dig Dis Sci 2005;50:757. 